\title{
Reseña
}

\section{Orgullo y Prejuicio. Reputación e Imagen de México.}

\author{
Elizabeth Bautista Flores*
}

Recibido: Mayo 2019

Aceptado: Diciembre 2020 ¿a reputación de un país se construye a través del tiempo y en ella se encuentran acciones y discursos que la sustenten. Esta reputación es resultado de la historia, sus conductas, sin duda son el atractivo que proyecta a otros y hasta en las contribuciones que, en su formación y desarrollo, ha aportado a la humanidad. De esa forma es posible que sean "los otros", quienes consolidan la buena reputación, debido a que se tienen referencias y percepciones positivas que llegan a ser ejemplo para personas o países. Así, a Francia se le refiere como una república progresista o el centro de amor y el romanticismo con su ya icónica Torre Eiffel; algo similar puede pasar con Italia y su gastronomía y el arte, o Rusia con su poderío armamentista y su intenso frío invernal.

Comprender esto desde el ámbito de la política es ampliar las perspectivas para el análisis interdisciplinario, como lo hace el investigador Leonardo Curzio, ya que pueden converger de manera más lúcida cuando se consideran perspectivas disciplinarias como la comunicación, la historia, la mercadotecnia e

incluso la antropología. En ese sentido se puede discutir la aportación del discurso y la acción como elementos de percepción con base en signos y estrategias comunicativas precisas, donde puedan estimular no sólo el deseo, las reminiscencias, sino también la fantasía, las experiencias y las aspiraciones.

E $\quad \mathrm{n}$ el caso particular que se ocupa en este texto, el investigador de la Universidad Nacional Autónoma de México (UNAM), escribió el libro titulado Orgullo y Prejuicio. Reputación e Imagen de México, donde lanza la primer interrogante: ¿a qué se debe la mala reputación de México?, en especial, cuando en la campaña para la presidencia de Estados Unidos, uno de los candidatos captó una gran cantidad de adeptos cuando parte de su discurso se cimentó en atacar al vecino del sur enfatizando los problemas que causa a la población estadounidense y los riesgos de no cerrar la frontera con lo que, de acuerdo a su propuesta, es necesario para protegerse de los migrantes.

El libro se compone de cinco capítulos o apartados, el primero de ellos es Las definiciones y aproximaciones teóricas relevantes, donde se brinda un contexto muy preciso no sólo del origen de libro, sino también la forma en la que se organizó el impreso y sus alcances a nivel teórico y conceptual; después, La naturaleza del problema, donde se explica muchas de las cuestiones históricas, geográficas y culturales que deben considerarse al momento de construir una narrativa; continúa con La construcción de una reputación, más tarde se incluyen datos cuantitativos sobre la percepción mundial; le sigue, La percepción externa de México, y concluye con las Líneas de acción y sugerencias, donde propiamente se brinda una rica reflexión y propuestas que pudieran ser de interés para quienes se dedican a la mercadotecnia, la comunicación y la política.

Este fue el escenario político que, en principio, discute y analiza el autor dado el proceso electoral estadounidense que culminó el 8 de noviembre de 2016, donde el entonces candidato Donald Trump, tomó como detonador para exacerbar el temor entre el estadounidense, así se mostró una poco favorable imagen de México y los mexicanos.

Con base en ello, se planteó una segunda interrogante por comprender la amplia recepción de un discurso agresivo y reduccionista sobre lo mexicano y los mexicanos en un segmento del electorado estadounidense, a pesar de que se tiene una historia, frontera, familias, y economía compartidas.

El doctor en política, Leonardo Curzio, recordó que dichas acusaciones existen desde hace más de 30 años cuando era presidente Miguel de la Madrid Hurtado, por lo que, desde entonces a la fecha, poco se ha realizado por invertir recursos para desarrollar acciones y plantearse objetivos que puedan revertir las acusaciones. Mas la cuestión no es de dónde proviene todo este discurso que ha tenido otras

\footnotetext{
* Doctora en Ciencias Sociales y Profesora de Tiempo Completo en la Universidad Autónoma de Ciudad Juárez. Contacto: bautistafliz@gmail.com. ORCID. https://orcid.org/0000-0002-2197-1493
} 
representaciones como Pete Wilson y Ross Perot, que, si bien no prosperaron, sí sembraron las semillas que, tal parece, ahora cosechó Trump. De esta forma, lo relevante son las acciones que se lleven a cabo y puedan dirigirse de forma correcta la reputación e imagen de un país como México.

Por lo tanto, el autor de este libro propuso un análisis sobre cuáles son las estrategias que deben implementar no sólo los gobiernos mexicanos, sino principalmente el Estado, que de manera institucional haga frente a los discursos que construyen las percepciones que son repetidas y continuamente desgastan la imagen de comercios, negocios, personas y países.

...a pesar de todos los intercambios fructíferos entre las dos naciones [México-Estados Unidos]. Estados Unidos no ve a México como un socio o como un aliado ni, menos, como un amigo, lo cual sí ocurre con respecto a Canadá. (: 13)

En ésta última se enfatizan los elementos discursivos para persuadir y ganar adeptos es posible que los contenidos tengan mayor carga de emociones y con ello, los componentes conductuales comiencen a aglutinarse en sentimientos como el orgullo por pertenecer a cierto grupo que se percibe como privilegiado, y que, precisamente, requiere de un grupo antagonista, es decir, aquellos ajenos, extraños, diferentes y excluidos. Aquellos que son una carga y peligro para mantener los privilegios, aquellos que se denominan con prejuicios debido a la desinformación o desconocimiento de lo que ocurre en su entorno.

De acuerdo con el autor, las autoridades mexicanas podrían considerar impulsar tres elementos para apuntalar las siguientes estrategias: a) Sustancia, que requieren acciones reales donde pueda cimentarse el entusiasmo o el ejemplo para otros; b) Narrativa, que es la forma de contar la propia historia "la habilidad para contar su propia historia de éxito... articular una narrativa poderosa, seductora para otras comunidades" (:22) y, por último, c) Canales de comunicación apropiados, los cuales son fundamentales para que el mensaje se transmita de manera correcta, pero además llegue a quienes se les desea enviar (segmento objetivo), y con ello, no sólo tener un impacto sobre lo enviado, sino que además se posicione ese contenido e influya en las opiniones de los mismos.

Bajo ese esquema vale la pena reflexionar sobre la situación en la que se ha desarrollado México, pues si bien su historia como país independiente es relativamente reciente, la intención por construir una reputación positiva ante el mundo nunca ha sido un punto clave en sus políticas de Estado, por lo que para mejorar la percepción se requiere, primero, de mejorar las acciones y luego el discurso, dejar de lado la parte folclórica y colorida para brindar mayor espacio a temas como el respeto a la ley, seguridad, igualdad de derechos y oportunidades de empleo.
A esta crítica debe añadirse el desarrollo de los medios de comunicación en México, ya que tuvo como sustancia, un origen demasiado cercano al poder político, lo cual siempre quedó la duda de quién debía más al otro, si los dueños de las radio y televisoras o los miembros del poder político; dicho vínculo tan estrecho les valió la creación de estereotipos hiperbólicos no siempre positivos ni tampoco con valores de superación, por lo que las narraciones, se fundamentaron en dramas ridículos y de conflictos absurdos, donde la mentira, la corrupción o el abuso se justificaron cotidianamente, por lo que fueron las acciones las cuales se mantuvieron como la constante, sin que se propusieran alternativas de cambio o al menos un promesa de progreso a las audiencias. El maltrato sistemático de las audiencias fue muy evidente

Por lo que habrá de recordarse que los empresarios mostraron poca ambición y creatividad para atender las necesidades de los consumidores, por lo que más de medio siglo repitieron historias en formatos de telenovelas, sin que se invirtiera en otros medios de comunicación como fue el cine, el teatro e incluso la misma televisión y la radio. En los diferentes países evolucionaron los modelos de negocios de los medios de comunicación, así como los contenidos, pero en México se mantuvo la historia de la sirvienta redimida entre la maternidad y el amor.

De ahí que las pocas producciones mexicanas en medios de comunicación sean de baja calidad dada la historia a contar y de raquítica producción, por lo tanto, es comprensible la carencia de contenidos aspiracionales, donde tengan impacto el Poder Blando (soft power), por lo que, en lugar de estimular y promover el orgullo propio, el respeto por el ser mexicano se optó por los contenidos burlescos o moralistas. En esos referentes se mantuvo oculta una acción que persigue como sombra a la mala reputación que antecede a México y es corroborado más tarde con la percepción que se tiene a nivel mundial y aceptado al interior.

Por lo anterior, vale la pena revisar el diagnóstico en el cual el autor desmenuza la situación en la cual se encuentra el interior México, aunque si bien se hace mención de hechos y situaciones no se brindan nombres de personas o empresas que son responsables y deben tener alguna participación en la construcción de esta reputación, donde los factores base son la confianza y respeto de lo que se trate de comunicar y a quien se dirige, pues ignorar la opinión o experiencias de los interlocutores se evitan las contradicciones entre lo que se predica con los hechos realizados.

La comunicación de las narrativas que se construyen en torno al producto [y que estimulan la imaginación] se sustentan en metáforas con argumentos y personajes. Al desplegarse estas historias de manera cotidiana en el universo mediático o en el ciberespeacio, se producen cristalizaciones de opinión que acaban

Vol. 10 Núm. 19 Julio-Diciembre 2020 
por ser aceptadas como representaciones convencionales... La representación de una marca (...) se convierte e un discurso estructurado y estructurante que limita los causes por los que se decodifica una realidad. Cambiar estas percepciones no es tarea sencilla (:49).

De tal manera que la política y la comunicación son dos disciplinas que se vincularon de manera más estrecha. Actualmente, esa unión se ha robustecido, al grado de que ahora la mercadotecnia domina en esos campos, a partir de la construcción de contenidos, donde son precisos los elementos visuales y emotivos para alcanzar un mayor número de personas, quienes además tienden a replicar ese contenido y llega a nivel de ser viralizado en pocas horas y se convierta en tendencia de la semana (trending topic).

Así como ahora, la pertinencia de este libro se mantiene sólida debido propiamente no tanto por el análisis realizado a lo que sucede en México y su entorno exterior, sino a la habilidad multidisciplinaria de considerar a la política como un campo de acción y decisión, pero robustecido con estrategias y herramientas de disciplinas como la Comunicación, dado ahora las nuevas tendencias de interacción en las redes sociales $\mathrm{y}$, en particular, de la Mercadotecnia, una disciplina relativamente más joven que las anteriores, pero de mayor impacto y penetración cuando se añaden elementos emocionales que son ahora las nuevas tendencias que marcan el posicionamiento de una marca o producto, dado el valor que se le asigne en un mercado, donde la percepción y la subjetividad son el punto de partida.

Por lo tanto, ahora es más válido revisar el pasado, las acciones actuales y reflexionar sobre las aspiraciones, pues definitivamente la interrogante queda más firme: ¿qué deben sentirse orgulloso los mexicanos? y limitar los prejuicios, no es cosa sólo de "los otros", es también el compromiso de quienes buscan comprender la importancia de la reputación, que se construye de manera cotidiana no sólo por lo que se diga, sino principalmente por las acciones que se realizan día con día. De eso que da gusto ser lo que se es.

\section{Referencias}

Curzio, L. (2016). Orgullo y Prejuicio. Reputación e Imagen de México. MA Porrúa, UNAM. CISAN. 152 pp. 